\title{
Study of Adding Cover-Plate Used For the Single Diagonal Eccentrically Braced Steel Frames
}

\author{
Xiuzhen Pan ${ }^{1, *}$ Jiping $\mathrm{Hao}^{2}$ and Jie Gao ${ }^{3}$ \\ ${ }^{1} X i$ ' an University of Technology, Institute of Water Resources and Hydraulic Power, Xi' an 710048, China \\ ${ }^{2} X i$ ' an University of Architecture \& Technology, School of Civil Engineering, Xi' an 710055, China \\ ${ }^{3}$ China United Northwest Institute for Engineering Design \& Research, Xi' an 710082, China
}

\begin{abstract}
This paper suggested a new connection protocol, adding cover-plate between shear links and column, which was used to enhance moment and shear carrying capacity of beam, relax the restriction and assure the sufficiency development of plastic deformation of the link, and dissipate more earthquake energy. Considering the scale ratio of 1:3, the experimental data was achieved by a specimen under cyclic loading, which was verified by nonlinear finite element analyses. Results indicated that the new type of eccentrically braced steel frame has enough stiffness and deformation capacity, draws link away from flange of column, and dissipates more earthquake energy. The single diagonal eccentrically braced frames adopted adding cover-plate protocol would ensure sufficient lateral stiffness under ordinary circumstances, including lateral loads due to wind and moderate seismic disturbances, have preferable resisting seismic behavior under rare earthquake, and be so practical and costly that they could be easily applied in the present project. Some factors which affect resisting seismic behavior were the thickness of the connection-plate between beam and column, adding stiffeners, and the decrease in the length of A segment etc.
\end{abstract}

Keywords: The Single Diagonal Eccentrically braced steel frame, Link beams, cover-plate, Shell element, Finite element.

\section{INTRODUCTION}

The D-type Eccentrically braced frame was a popular resisting forces system. When the shear link joined the column directly, the flexural capacity of beam should be big enough while the restriction couldn't be too great [1-4]. It should avoid lamellar tearing, and assure the sufficiency development of plastic deformation in order to dissipate earthquake energy. [5, 6].

Experiments have shown that welded link-to-column connection tends to fracture in the link flange before the occurrence of a large rotation of the link The American Institute of Steel Construction (AISC) seismic provisions warn designers of the problems with link-to-column connections and indicate they should be the subject of ongoing research. AISC sponsored this pilot study to investigate the effectiveness of removing portions of the EBF link web in an attempt to limit forces that could develop in the flanges and thereby increase connection rotation capacity. Richards used data from previous experiments IN which the link web was pierced with holes to reduce stress and strain as indicated by the value of link flanges at the connection, however, the plastic strain and stress triaxility were increased in the web at the edges of the holes [7]. Nineteen shear yielding link finite element models were analyzed under cyclic loading. The

*Address correspondence to this author at the Xi' an University of Technology, Institute of Water Resources and Hydraulic Power, Xi' an 710048, China; Tel: +86-29-82312906; Fax: +86-29-83239907;

E-mail: 13571828178@163.com rotation capacity of Links with reduced web sections is similar to, or less than the inks with no web reductions which fail in the flanges. This study indicates that reducing web section is not a promising solution to the problem.

The design of link-to-column connections in seismicresistant eccentrically braced frames remains a largely unresolved problem. In order to address this problem, Taichiro Okazaki tested twenty-four large-scale specimens under cyclic loading [8]. The test parameters included the connection detail, link length, link section, and cyclic loading protocol. The test results suggest that link-to-column connections are susceptible to fracture at the link flange welds, and the link length have little effect. A large number of specimens failed prematurely, before meeting the plastic link rotation requirement in US code provisions. However, two promising link-to-column connection details were developed as an outcome of this research. One of the new connection details use all-around fillet welds between the link and the column flange. And another is a reinforced one, in which the link web was welded a pair of stiffeners. Test specimens using either of these two details were able to exceed the plastic link rotation requirement.

Some strengthening measures were taken in order to meet the design demand of "strong column-weak beam and stronger connection capacity". How about will these protocols be used for eccentrically braced steel frame?

A new connection protocol between shear link and column, adding improved cover-plate, was introduced to the 
Eccentrically Braced Frame to enhance moment and shear bearing capacity of the beam with the traditional reinforced connection method. The new reinforced connection protocol has got issued patent [9]. The experimental investigation and theoretical analysis are conducted in this paper.

\section{THE DESIGN OF ADDING IMPROVED COVER- PLATE}

The improved cover-plate protocol used in the D-type eccentrically braced system was presented in Fig (1). The protocol of widening local beam cross-section was taken to reinforce the moment and shear resisting capacity. Wedge cover plates were welded both on the top and bottom beam flanges. A connection plate was welded on the column with shop fillet welding. The holes on beam web were prepared for connection. The column and beam were connected by high strength bolts in field, the connection plate and beam web were welded by single fillet welding. At last, the top and bottom flange were connected with column with penetration weld.

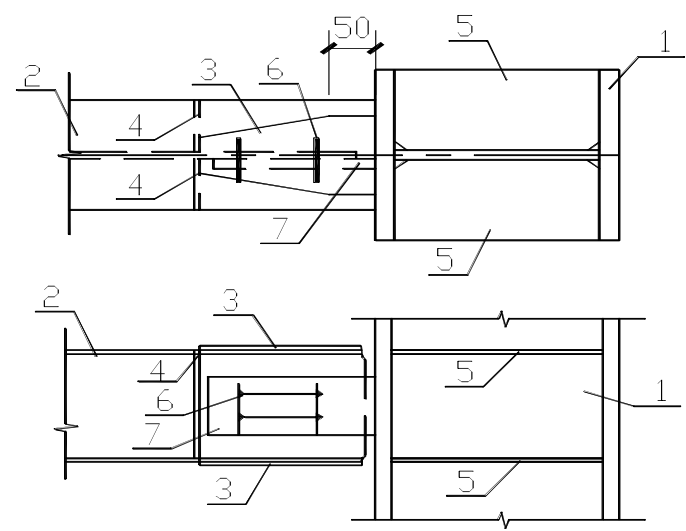

Note : 1-column,2-beam,3- trapezoidal cover plate, 4-stiffener of link, 5-stiffener of column, 6- high strength bolt, 7-gusset.

Fig. (1). The improved cover plate protocol.

Therefore, the beam flange and web were reinforced effectively. But the Premise condition of using the new protocol was that the link must be sheared and the link and reinforced connection must have sufficient lateral stiffness to bear lateral loads, such as wind load and seismic load.

\section{TEST SPECIMENS}

A 1:3 scale specimen was designed as shown in Fig. (2). The dimension of the cover plate was $180 \times 100 \times 6$. The length of link was $240 \mathrm{~mm}$ according to the design requirements [10, 11]. Transverse stiffeners were set in the web of link in order to avoid transverse torsion yielding under the cycle loading. The stiffeners with a thickness of $10 \mathrm{~mm}$ were welded to the link's web, and the spacing of the stiffeners was $80 \mathrm{~mm}$.

\section{EXPERIMENTL PROGRAM}

\section{Loading Protocal and Test Setup}

The specimen was tested on static support. The column bases were fixed on the girder by high strength bolts. The girder was fixed on the static support by anchor bolts. On the top floor roller braced were set as lateral restraint to prevent the out-of-plane buckling.

As shown in Fig. (2), the experiment loads concludes horizontal and vertical load. In order to simulate the weight of the roof, floor and walls, a $400 \mathrm{KN}$ load was imposed on the top of the column by hydraulic jacks. Horizontal cyclic load were imposed through the centerline by reaction frame to stimulate earthquake force.

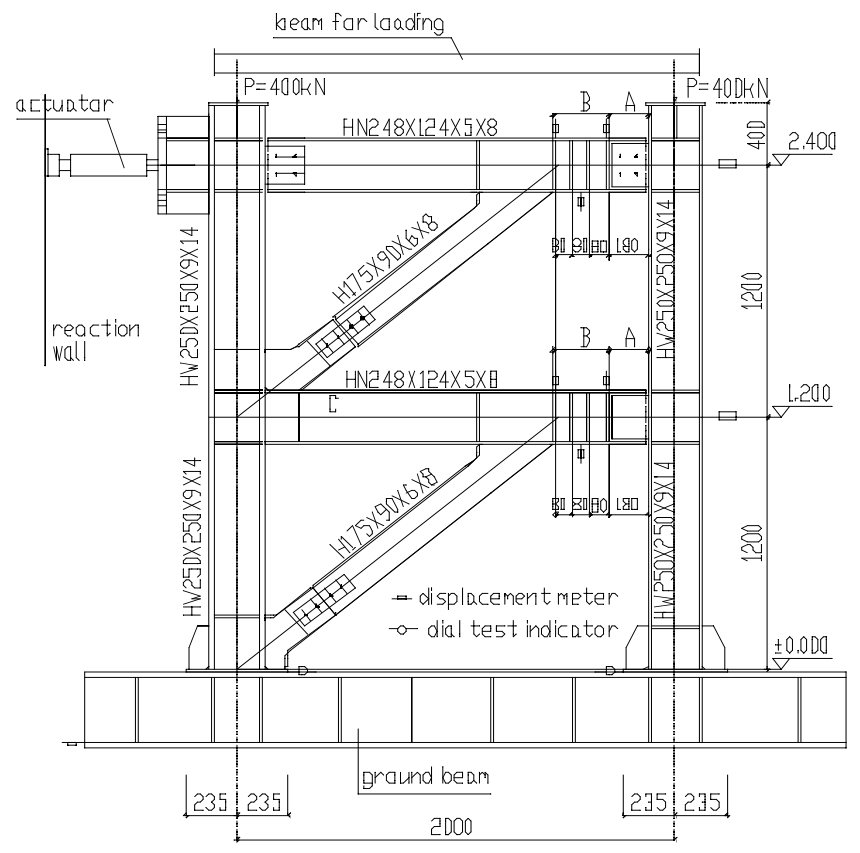

Fig. (2). Diagram of the specimen.

The horizontal loads were controlled by force value and displacement [12]. Before the specimen yield, the test was controlled by force value. After yielding, the control method was switched to displacement control. The displacement value introduced the peak level of displacement value $\Delta_{\mathrm{y}}$. Before yielding every step circulated one time and after yielding it circulated three times.

\section{Instrumentations}

The instrument layout was shown in Fig. (2), nine displacement gauges and two dial Indicators were set. The displacement gauges were used to test the displacement of upper floor, the relative displacement within each floor and the rotation of the link. The dial indicators were used to measure the drift between the column base and the girder. The strain gauges and rosettes were used to measure the stress distribution of the components.

\section{Initial Flaw of Specimen}

The distance of the column top deviating foot that caused by welding joint of flange and web was $6 \mathrm{~mm}$. Two initial flaws were shown in Fig. (3). Welds were not very good. The centre line of bolts and axes of brace was not superposition which would cause contact extrusion between bolt pole 


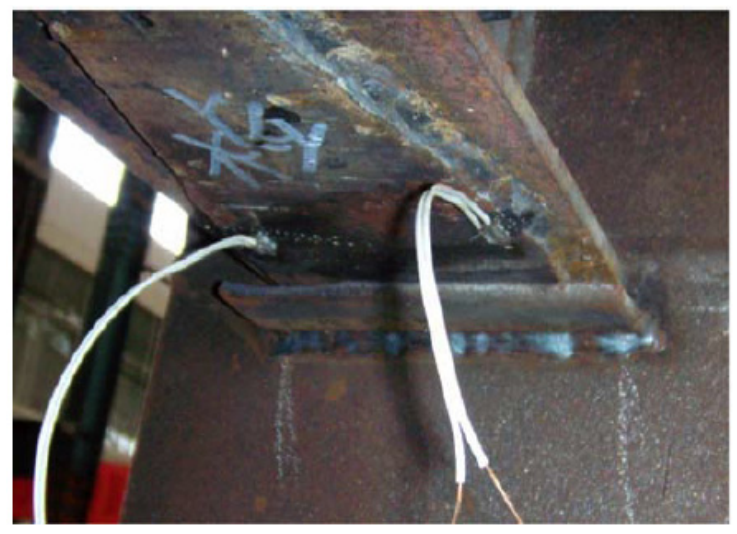

(a) Joint of the top beam and column

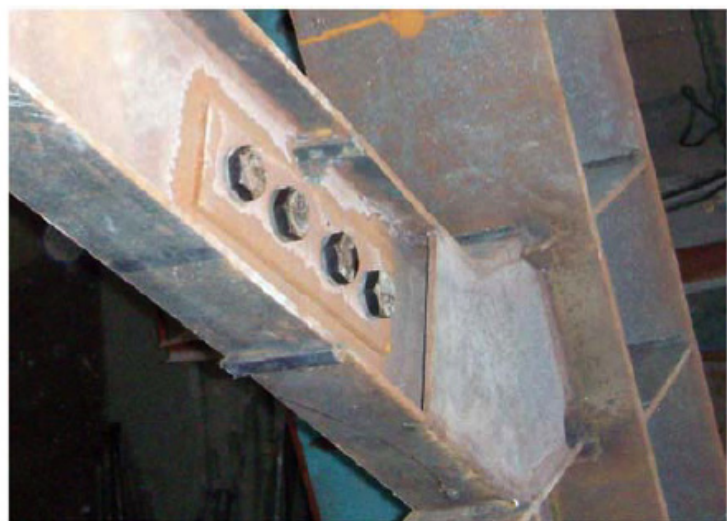

(b) Joint of the top brace

Fig. (3). Initial flaw of specimen.

and wall of hole. All above flaws would lead to experimental error.

\section{Failure Mode}

The specimen failure modes with different loading levels were presented in Fig. (4). With the increase of the horizontal load, when $F_{y}=384.73 \mathrm{kN}$, the web of the link in the top floor began to wrinkle and stepped into the plastic phase, the

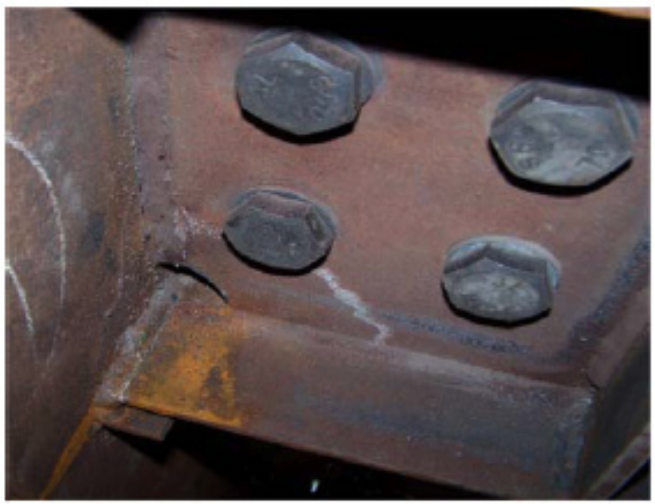

(a) The top beam joint of $2 D_{y}^{3}$

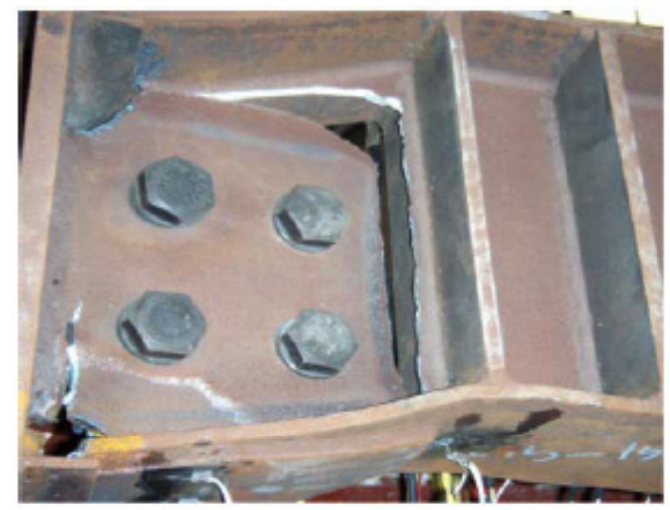

(c) The top beam joint of $4 \mathrm{D}_{y}^{1}$ rotation was $0.00617 \mathrm{rad}$. Then the control was switched from the loading control to the displacement control. The increment of every level was $\Delta_{y}=8.76 \mathrm{~mm}$.

In the first circular level, the rotation of the link was notable and it reached to $0.011 \mathrm{rad}$. The web of the link in the first floor shrank and stepped into the plastic phase, and meanwhile the link began to rotate. In the second circular level, the rotation of the link in the top floor was $0.0446 \mathrm{rad}$.

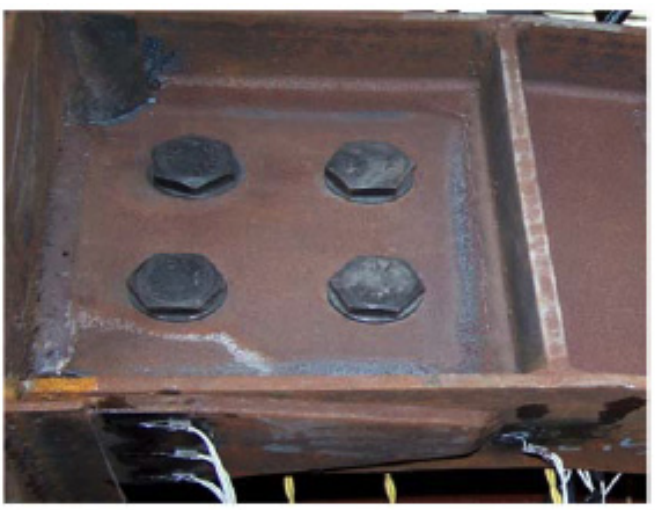

(b) The top beam joint of $3 \mathrm{D}_{y}^{1}$

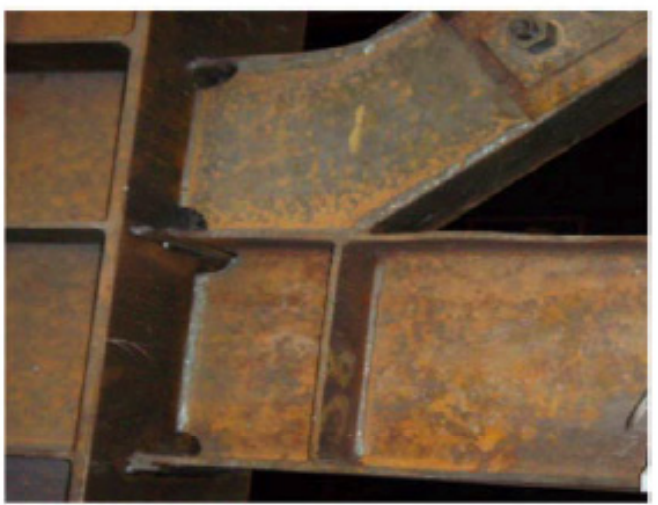

(d) The bottom beam joint of $4 \mathrm{D}_{y}^{1}$

Fig. (4). The failure mode of the specimen of different loading levels. 
it is the first time that some little crack appeared on the top of the welds in the bottom flange which was in the area of link-to-column joint, just as Fig. (2) shown. Then the incision in the bottom of the web, presented in Fig. (4a), and the links got notable rotation without failure. In the third circular level, the link of the top floor got notable rotation. The rotation achieved $0.077 \mathrm{rad}$.

Some little crack appeared in the welds with the web and the connection plate, which was shown in Fig. (4b). The crack in the bottom flange increase but the link in the first floor still performance . The rotation of the link in the first floor achieved $0.0788 \mathrm{rad}$. The rotation with region $\mathrm{A}$ was also large, and the web crack of region A tore along the flanges in the horizontal and the welding line in the vertical.

In the fourth circular level, the rotation of the link in the top floor achieved to $0.0878 \mathrm{rad}$, and the bottom flange in A tore wholly but the top flange perform well as shown in Fig. $(4 \mathbf{c}$ and $\mathbf{d})$. Then the test was terminated. The column inclined obviously. As presented in regional $\mathrm{C}$ which was marked in Fig. (2), slightly local buckling appeared in this region. Meanwhile the link had greater rotation but performed without failure. The two bottoms of the brace and the column were still in the elastic phase.

Some failure modes could be observed from the experiment. First of all, all links yielded because of the achievement of the limit shear capacity. The bending hinges were formed first in the flange of beams, and the shear hinges were formed in the web. It implied that the beam could bear large moment and shear force. Secondly, with the increase of the internal forces in region $\mathrm{A}$, the cracks appeared from the flange welding, web incision and the welding near the connection plate, and failed because the development of cracking. With the increase of loading, greater rotation created in region A led to the notable change of the loop of the link. Thirdly, proper measures were taken to reinforce the flange and web at the end of the beam, and it could avoid the formation of plastic hinge effectively. Fourthly, in the first floor, the internal force in the connection of the beam and brace was very great. So strengthen measure should be taken to avoid yielding in this region.

\section{Test Results and Analysis}

The hysteretic curve of horizontal force-lateral displacement was presented in Fig. (5). In the elastic phase, hysteretic curve was nearly linear. The energy absorbed in the elastic phase were all transformed into kinetic energy; After the link began to yield, the area surrounded by hysteretic curve was the energy dissipation. More and more residual deformation was produced at sequent cycles. The hysteretic loop was plump like a spindle. In addition, the hysteretic loops were a little disorganized in the $\Delta_{y}$ phase and a little

pinch in the $3 \Delta_{y}$ phase. The poor quality of construction and the initial defect led to the premature formation of the plastic hinge. Almost no pinch appeared in hysteretic loops. The results showed that the new protocol used in the D-type eccentrically braced frame had good energy dissipation.

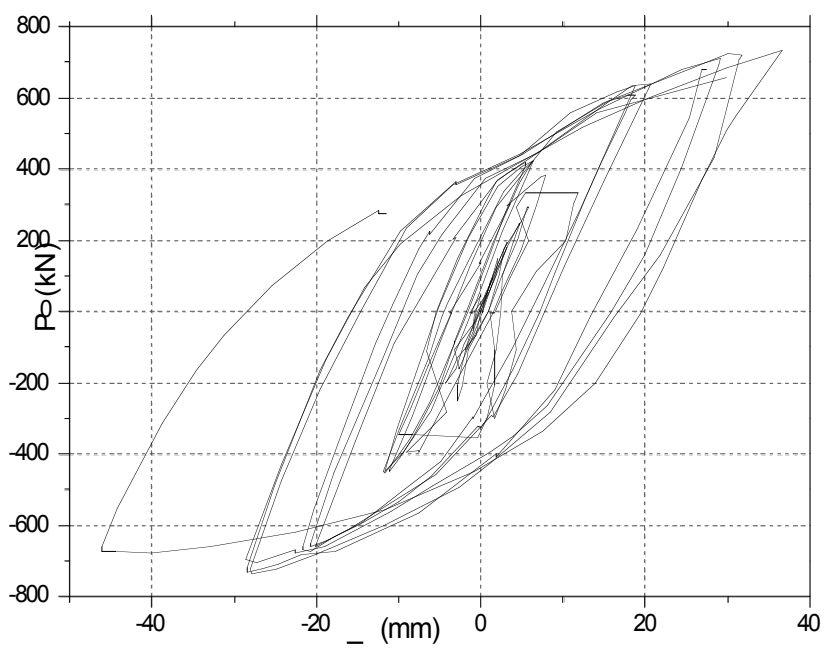

Fig. (5). $P-\triangle$ hysteretic curve.

The hysteretic curve of horizontal force-link rotation was presented in Fig. (6). The hysteretic loop was like a spindle, plump and stable. The area surrounded by loops was large and no pinch. When the horizontal displacement reached $3 \Delta_{y}$, notable drift appeared in the hysteretic loop. It was because of the large rotation in A region of top floor. The results showed that the link had good energy-dissipation performance.

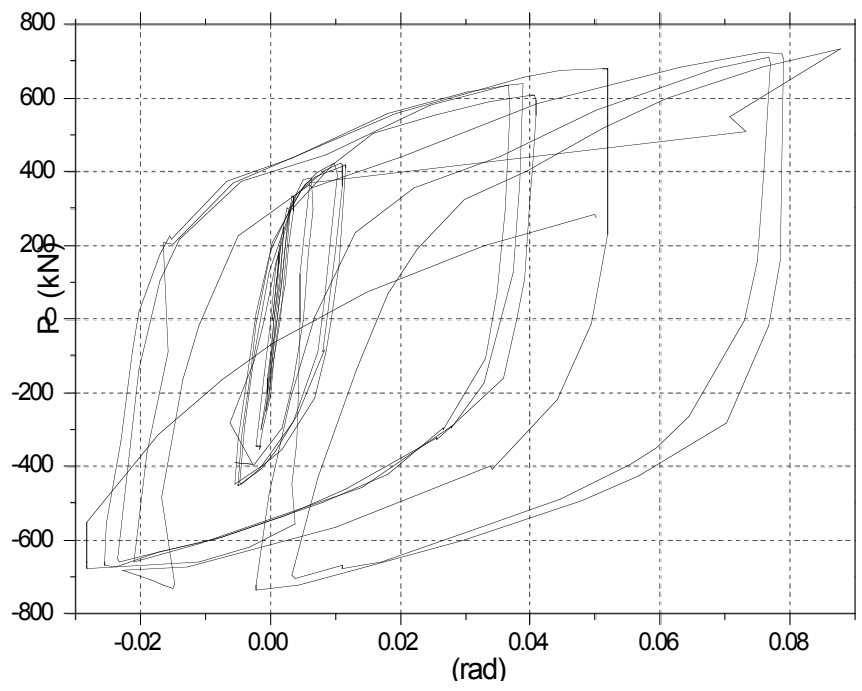

Fig. (6). $P-\theta$ hysteretic curve.

It could been observed in Table 1 that the ductility coefficient was greater than 3 , so the specimen had a good ductility performance, the displacement of the top column added up to $37.44 \mathrm{~mm}$, the structural rotation $\Delta_{u} / H=1 / 64(\mathrm{H}$ was the specimen height) was less than the allowable value of the elastic-plastic drift angle 1/50 listed in literature5. The specimen had sufficient lateral stiffness; the limit of link rotation was $0.0878 \mathrm{rad}$, be close to $0.1 \mathrm{rad}$ [13]. 
Table 1. The Experiment Result Under Cycle Loading

\begin{tabular}{|c|c|c|c|c|c|c|c|}
\hline $\begin{array}{c} \pm \mathrm{P}_{\mathrm{y}} \\
/ \mathrm{kN}\end{array}$ & $\begin{array}{c} \pm \Delta_{\mathrm{y}} \\
/ \mathrm{mm}\end{array}$ & $\begin{array}{c} \pm \mathrm{R}_{\mathrm{y}} \\
/ \mathrm{rad}\end{array}$ & $\begin{array}{c} \pm \mathrm{P}_{\mathrm{u}} \\
/ \mathrm{kN}\end{array}$ & $\begin{array}{c} \pm \Delta_{\mathrm{u}} \\
/ \mathrm{mm}\end{array}$ & $\begin{array}{c} \pm \mathrm{R}_{\mathrm{u}} \\
/ \mathrm{rad}\end{array}$ & $\pm \mu$ \\
\hline 384.73 & 8.76 & $6.17 \mathrm{e}-3$ & 735.1 & 37.44 & 0.0878 & 4.27 \\
-393.3 & -8.31 & $-2.75 \mathrm{e}-3$ & -735.2 & -27.02 & -0.0024 & 3.25 \\
\hline
\end{tabular}

\section{FINITE ELEMENT ANALYSIS}

The specimens were analyzed with nonlinear finite element analysis by ANSYS. The theoretic results and experiment results were compared in order to analysis the failure mechanism of the new D-type eccentrically braced frame which the new connection schemes were applied in.

\section{Finite Element Modeling}

The three dimensional, eight joints, six freedom , large deformation, small strain finite element shell 143 was conducted in this paper using Von Mises yielding criteria, relevant stream criteria, and multi-linear intensify rule. The steel's elastic modulus $E=1.83364 \times 10^{5} \mathrm{~N} / \mathrm{mm}^{2}$, Poisson ratio $\mu=0.3$, the construction relation was elicited from the tension experiment of plate in Fig. (3). The finite element model was built by ANSYS as shown in Fig. (7).

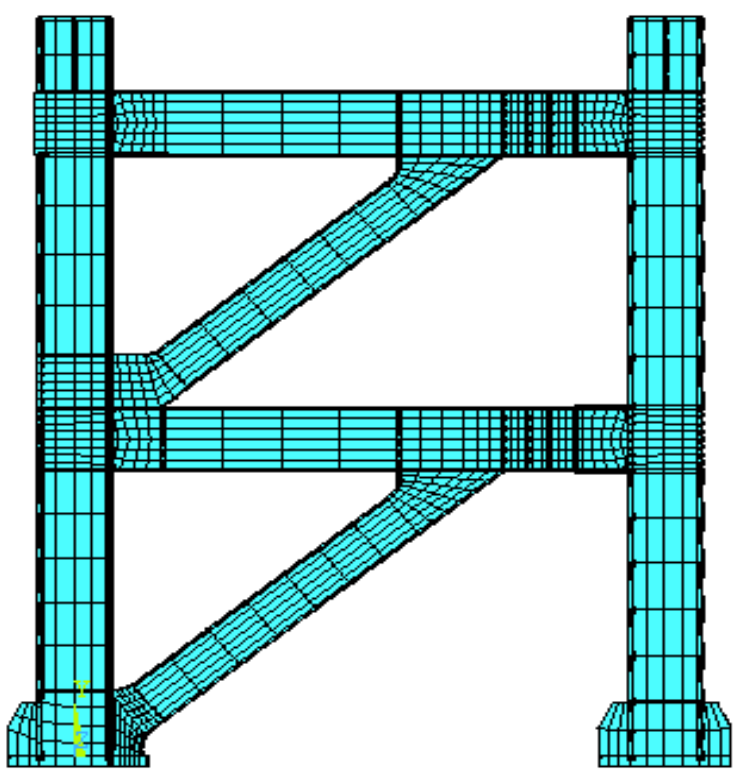

Fig. (7). Finite element model.
The performance under unilateral loading and cycle loading was calculated by the ANSYS. The results were listed in Table 2.

\section{The Finite Element Analysis}

The Von Mises stress distribution when the specimen reached limit capacity was presented in Fig. (8). Both under unilateral and cycle load, the three parts of the link in the top floor yielded almost at the same time The shearing force continued to increase due to strain-hardening effect, and the web of the link subsequently yielded. When the specimen reached limit capacity, plastic hinges were formed in the web of the link, and the bending hinges were formed in the flange at the end of the beam. When the structure reached the limit capacity, the whole web of the link formed shear hinges while the flange of the beam end did not yield.

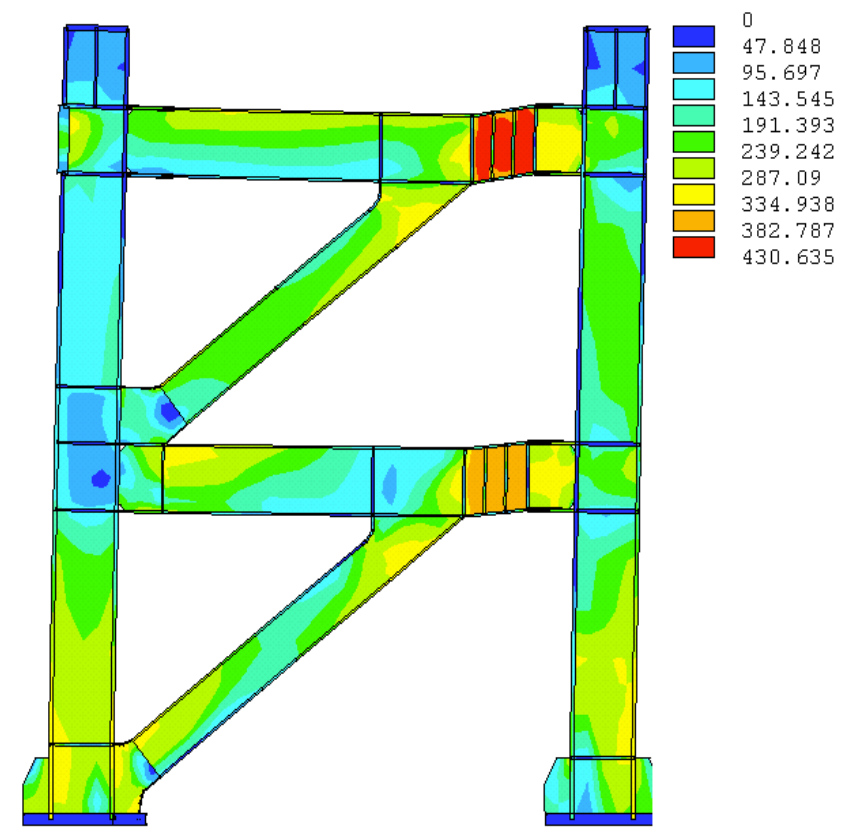

Fig. (8). The stress distribution.

Table 2. The Results of Finite Element Analysis Under Two Protocols

\begin{tabular}{|c|c|c|c|c|c|c|c|c|c|c|c|c|c|}
\hline \multicolumn{6}{|c|}{ Unilateral Loading } & \multicolumn{8}{|c|}{ Circular Loading } \\
\hline $\begin{array}{c}\mathrm{P}_{\mathrm{y}} \\
/ \mathrm{kN}\end{array}$ & $\begin{array}{c}\Delta_{\mathrm{y}} \\
/ \mathrm{mm}\end{array}$ & $\begin{array}{l}\mathrm{R}_{\mathrm{y}} \\
/ \mathrm{rad}\end{array}$ & $\begin{array}{c}\mathrm{P}_{\mathrm{u}} \\
/ \mathrm{kN}\end{array}$ & $\begin{array}{c}\Delta_{\mathrm{u}} \\
/ \mathrm{mm}\end{array}$ & $\begin{array}{l}\mathrm{R}_{\mathrm{u}} \\
/ \mathrm{rad}\end{array}$ & $\begin{array}{l} \pm \mathrm{P}_{\mathrm{y}} \\
/ \mathrm{kN}\end{array}$ & $\begin{array}{l} \pm \Delta_{\mathrm{y}} \\
/ \mathrm{mm}\end{array}$ & $\begin{array}{l} \pm \mathrm{R}_{\mathrm{y}} \\
/ \mathrm{rad}\end{array}$ & $\begin{array}{l} \pm \mathrm{P}_{\mathrm{u}} \\
/ \mathrm{kN}\end{array}$ & $\begin{array}{l} \pm \Delta_{\mathrm{u}} \\
/ \mathrm{mm}\end{array}$ & $\begin{array}{l} \pm \mathrm{R}_{\mathrm{u}} \\
/ \mathrm{rad}\end{array}$ & $\mu$ & $\mu_{\mathrm{r}}$ \\
\hline 367 & 5.83 & $2.9 \mathrm{e}-3$ & 796 & 50.8 & 0.142 & $\begin{array}{c}364 \\
-388\end{array}$ & $\begin{array}{c}6 \\
-6\end{array}$ & $\begin{array}{l}2.82 \mathrm{e}-3 \\
-3.2 \mathrm{e}-3\end{array}$ & $\begin{array}{r}740 \\
-782\end{array}$ & $\begin{array}{c}36 \\
-36\end{array}$ & $\begin{array}{c}0.107 \\
-0.092\end{array}$ & $\begin{array}{l}6 \\
6\end{array}$ & $\begin{array}{l}37.9 \\
28.8\end{array}$ \\
\hline
\end{tabular}


Some conclusion could be got from Table 2. The limit rotation of the link were greater than $0.1 \mathrm{rad}$ under the two loading protocols, and the ductility coefficient of angular displacement was greater than 3 , so the specimen had a good rotational capacity. It could seen that the specimen have good ductility. When the structure reached the limit capacity, the two ends of the brace and the column reached the limit capacity, the other components were still in the elastic phase. It was consistent with in the design requirements listed in the literature5.

\section{The $P-\Delta$ Curve and $P-\theta$ Curve of Link Under Unilat- eral Loading}

The $P-\Delta$ curve and $P-\theta$ curve of link under unilateral loading were presented in Figs. (9 and 10). The unilateral loading curve was linearity strengthened. The displacement of the top column added up to $50.83 \mathrm{~mm}$, the structural rotation $\Delta_{u} / H=1 / 47$ was more than the allowable value of the elastic-plastic drift angle 1/50 listed in literature5. The specimen had sufficient lateral stiffness; the limit of link rotation was $0.092 \mathrm{rad}$, close to the $0.1 \mathrm{rad}$ [13]. It could relax the extreme local deformation in the link flanges, and allow more link rotation.

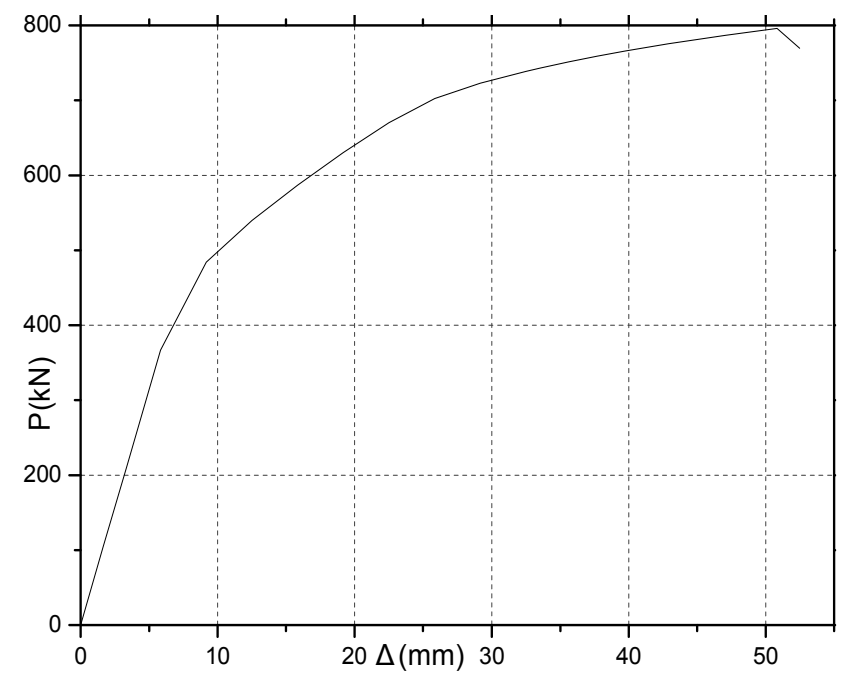

Fig. (9). $P-\Delta$ curve under unilateral loading.

\section{The $\boldsymbol{P}-\Delta$ Curve Under Circular Loading}

The $P$ - $\Delta$ hysteretic curve under circular loading (horizontal force - displacement loop) was presented in Fig. (11). It could be seen that the hysteretic loops were plump, stable like a spindle, and no pinch. After yielding, the stiffness degenerated when reverse loading were imposed. Significant Bauschinger effect could be observed. The finite element analysis did not consider the initial defects such as geometry defect and welding residual stress. Compared with the experimental results, the P- $\Delta$ hysteretic curve of the theoretical results were plumper. It showed that as long as the beamcolumn connections were really strengthened by proper construction details, the specimen would show good energydissipation characteristic.

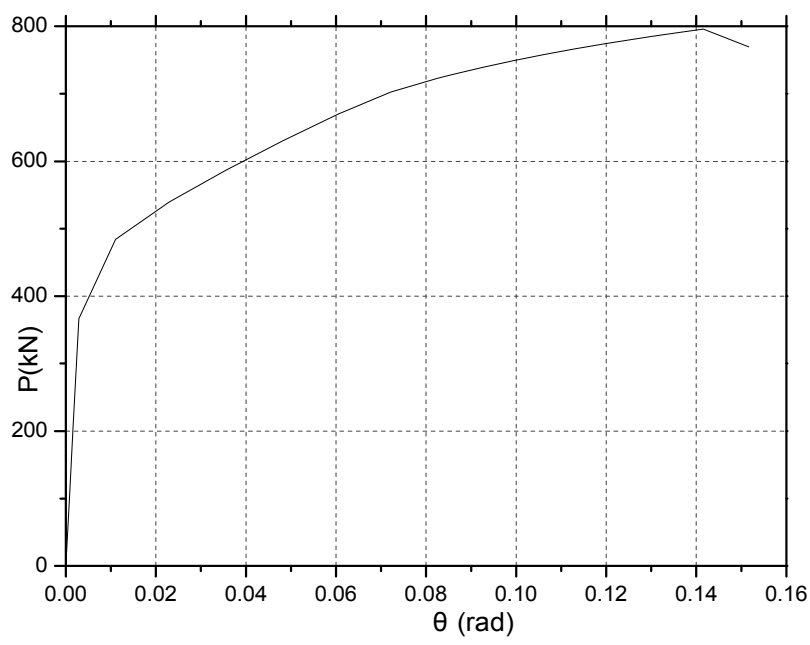

Fig. (10). $P-\theta$ curve under unilateral loading.

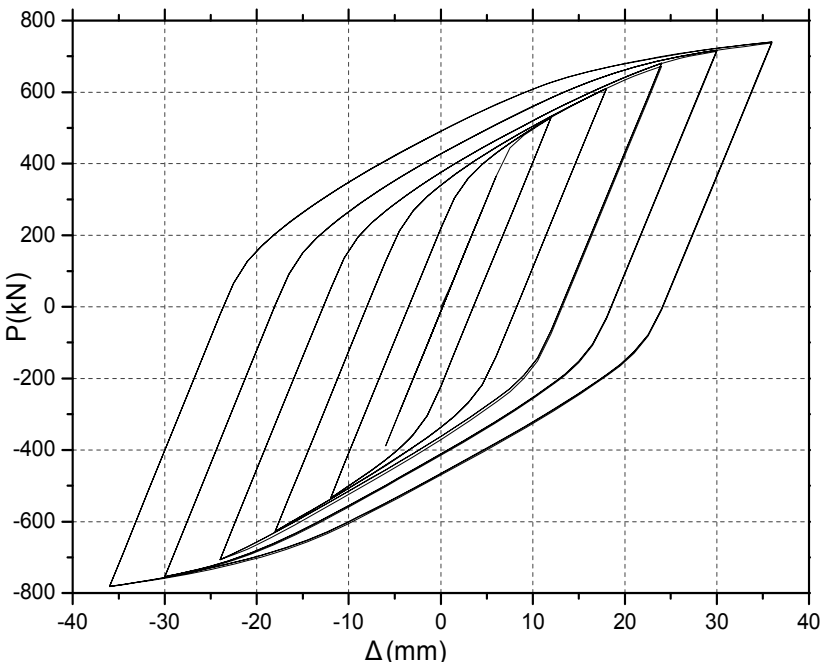

Fig. (11). $\mathrm{P}-\Delta$ hysteretic curve.

\section{The $\boldsymbol{P}-\boldsymbol{\theta}$ Curve of The Link Under Circular Loading}

The $P-\theta$ loop of the link under circular loading was presented in Fig. (12). It was observed that the hysteretic loop was plump, stable, triangular, and no pinch. The limit rotation of the link achieved 1.108rad. The experimental results showed that the link did not develop the rotation capacity sufficiently, because tearing occurred in region A and it led to the termination of the experiment. Therefore, the finite element results were far higher than the experimental results, and the links had better rotation capacity.

\section{The Framework Loops}

The pink points of the first-cycle were connected to form the framework loop as shown in Fig. (13). It was observed that the theoretic capacity and the displacement were in consistent with the experimental results in the elastic phase. After the link yielded, the theoretic capacity, and the displacement were less than the experimental results because when 
the Mises equivalent stress achieved the ultimate strength or the other component except the link yielded, the ANSYS would identify the frame to be failure. But in fact when the Mises equivalent stress achieved the ultimate strength or the other component except the link yielded, the whole frame would not lose its capacity to bear loading until the failure of the specimen and the termination of tests.

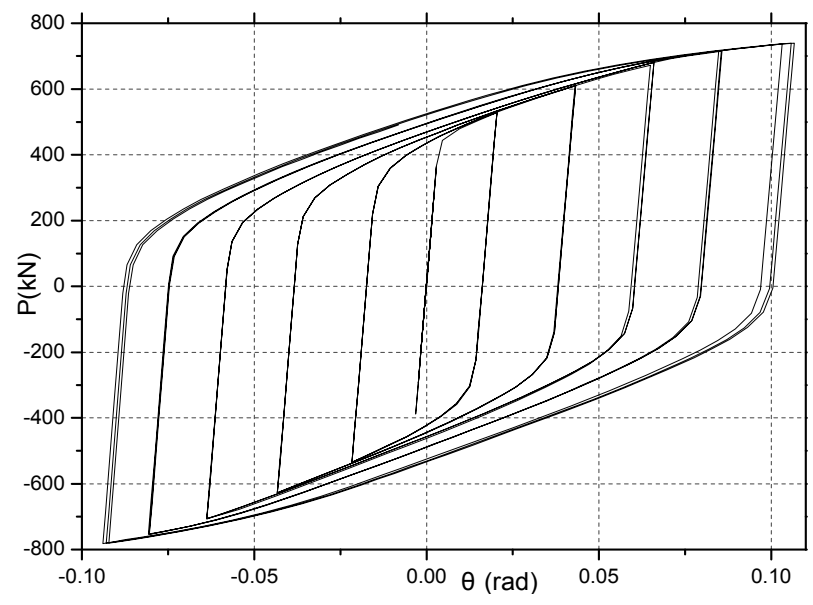

Fig. (12). $\mathrm{P}-\theta$ hysteretic curve.

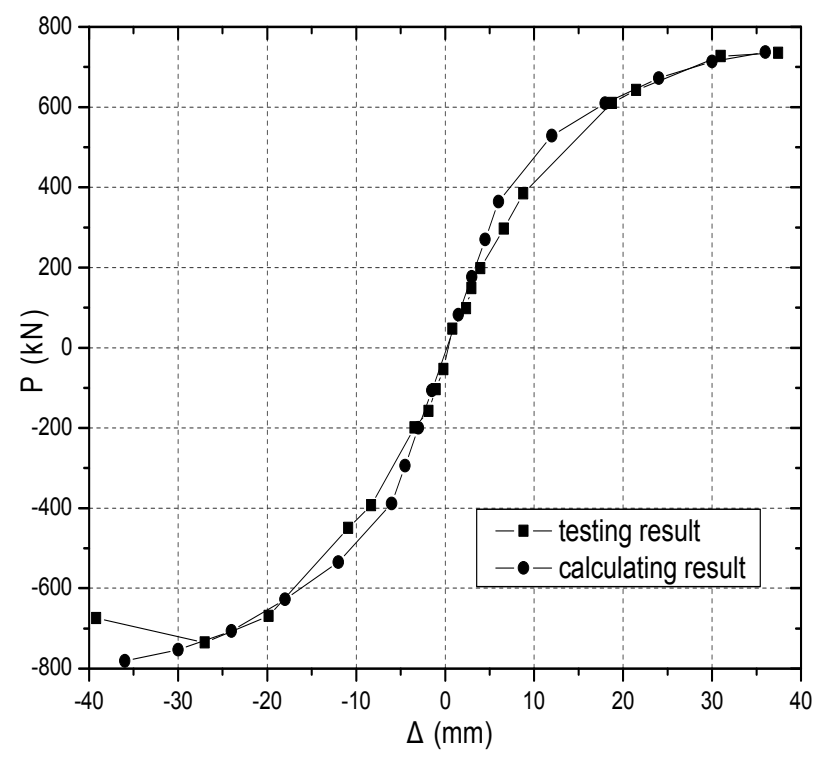

Fig. (13). Framework loops.

\section{Stiffness Degenerated Curve}

Following the provision in the literature 8 , the stiffness of the frames was illustrated by the secant stiffness. Fig. (14) showed degradation of the non-dimensional displacement and stiffness. $\mathrm{K}$ was the stiffness, $\mathrm{K}_{0}$ was the initial stiffness, $\Delta$ was the horizontal displacement and $\Delta_{\mathrm{y}}$ was the yield displacement.
In elastic stage, the experimental stiffness was with about $70 \%$ degeneracy of initial stiffness and trembled, but the theoretic stiffness basically held 1.0. When the link began to yield, the experimental stiffness maintained as low as $50 \%$ internal stiffness which was greatly lower than that the theoretic stiffness. With the cyclic number increasing, the stiffness degradation gradually reduced. When specimen entered the ultimate stage, the experimental stiffness kept $18.6 \%$ internal stiffness, the theoretic stiffness kept $35 \%$ internal stiffness. So the specimen had good deformation capacity and lateral stiffness as long as strengthen measure should be taken to avoid yielding of A region.

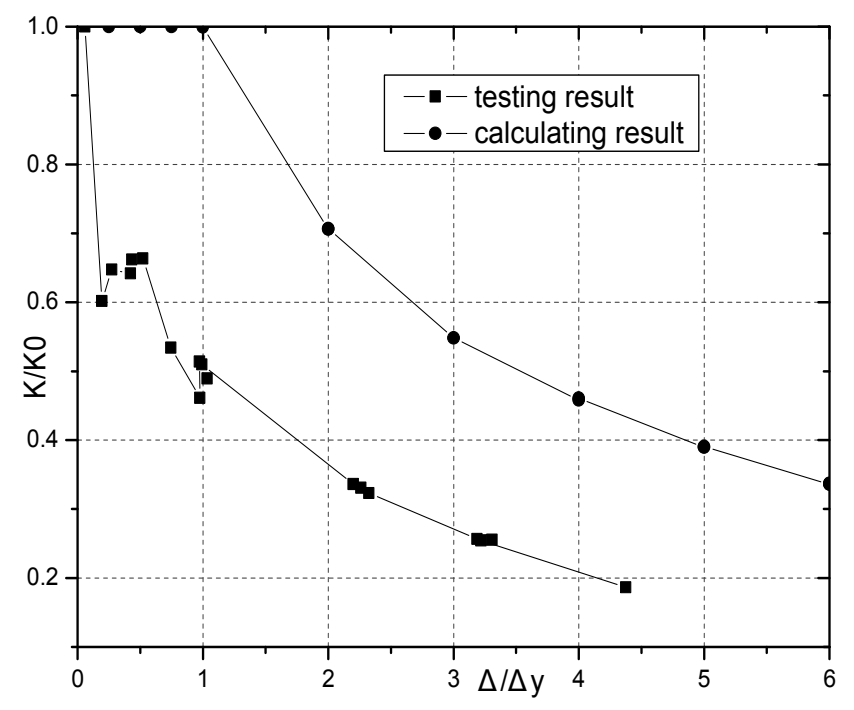

Fig. (14). Stiffness degenerated curve.

\section{STUDY OF RELEVANT PARAMETERS}

\section{The Influence of Cover-Plate Thickness in A Region}

The cover-plate thickness in A region was increased, and the other parameters were unchanged. Two finite element models were built apart adopting cover-plate thickness with $10 \mathrm{~mm}$ and $12 \mathrm{~mm}$. The performance under unilateral loading and cycle loading were calculated by the ANSYS. The results were listed in Table 3.

The $P-\Delta$ and the $P-\theta$ curve under unilateral loading were presented apart in Figs. (15 and 16). The stress distribution of the cover-plate thickness with $10 \mathrm{~mm}$ was shown in Fig. (17) when specimen reached the limit capacity under circular loading. Some conclusion could be drawn as follows.

With the thickness of cover-plate increasing, the limit rotation capacity of link and limit capacity of frame were almost unchanged under unilateral loading and increased a little under circular loading, the Mises stress in A region was decreased slightly, the stiffness of frame was unchanged basically. When eccentrically brace frame was designed, the thickness of cover-plate in A region should meet structure requirements, not be strengthened especially. 
Table 3. The Results of Finite Element Analysis

\begin{tabular}{|c|c|c|c|c|c|c|c|c|}
\hline $\begin{array}{l}\text { Cover-Plate } \\
\text { Thickness }\end{array}$ & Loading Protocol & $\begin{array}{c}\mathbf{P}_{\mathbf{y}} \\
/ \mathbf{k N}\end{array}$ & $\begin{array}{c}\Delta_{\mathbf{y}} \\
/ \mathbf{m m}\end{array}$ & $\begin{array}{c}\mathbf{R}_{\mathbf{y}} \\
/ \mathbf{r a d}\end{array}$ & $\begin{array}{c}\mathbf{P}_{\mathbf{u}} \\
/ \mathbf{k N}\end{array}$ & $\begin{array}{c}\Delta_{\mathrm{u}} \\
/ \mathrm{mm}\end{array}$ & $\begin{array}{c}\mathbf{R}_{\mathrm{u}} \\
/ \mathbf{r a d}\end{array}$ & $\mu$ \\
\hline $12 \mathrm{~mm}$ & unilateral loading & 371.8 & 5.83 & $2.84 \mathrm{e}-3$ & 787.1 & 50.83 & 0.1451 & 8.72 \\
\hline \multirow[t]{2}{*}{$10 \mathrm{~mm}$} & \multirow{2}{*}{ cycle loading } & 367 & 6 & $2.782 \mathrm{e}-3$ & 744.7 & 36 & 0.1053 & 6 \\
\hline & & -391 & -6 & $-3.16 \mathrm{e}-3$ & -785 & -36 & -0.0944 & 6 \\
\hline
\end{tabular}

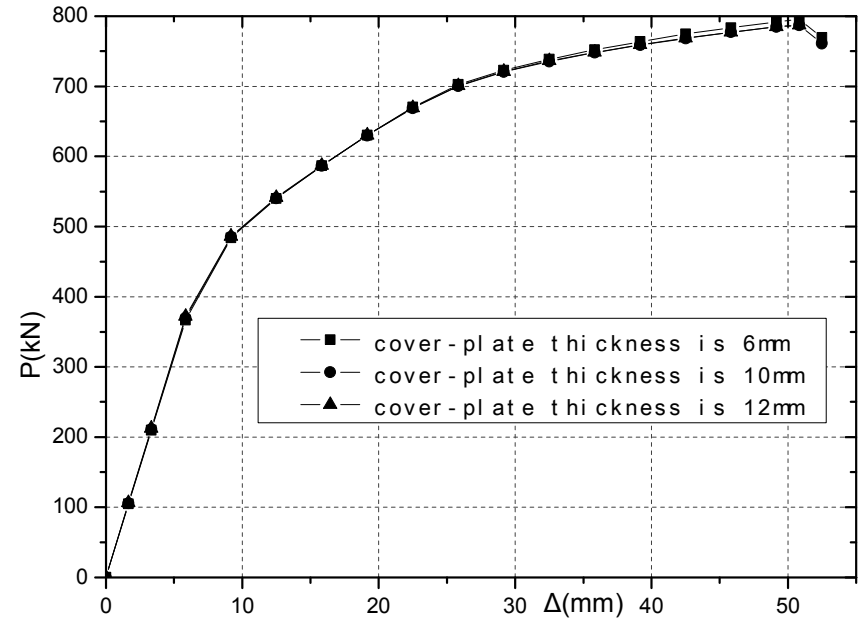

Fig. (15). $P-\Delta$ curve comparing under unilateral loading.

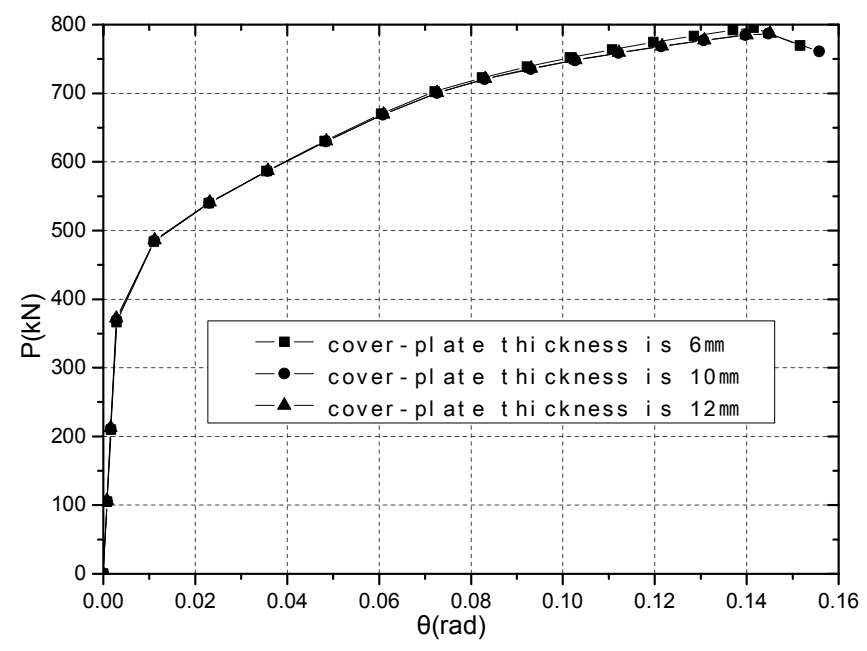

Fig. (16). $\mathrm{P}-\theta$ curve comparing under unilateral loading.

\section{The Influence of Web Thickness in A Region}

The web thickness in A region was increased, and the other parameters were unchanged. Two finite element models were built apart adopting web thickness with $14 \mathrm{~mm}$ and $16 \mathrm{~mm}$. The performance under unilateral loading and cycle loading were calculated by the ANSYS. The results were listed in Table 4.

The $P-\Delta$ and the $P-\theta$ curve under unilateral loading were presented apart in Figs. (18 and 19). The stress distribu- tion of the web thickness with $14 \mathrm{~mm}$ was shown in Fig. (20) when specimen reached the limit capacity under circular loading. Some conclusion could be drawn as follows.

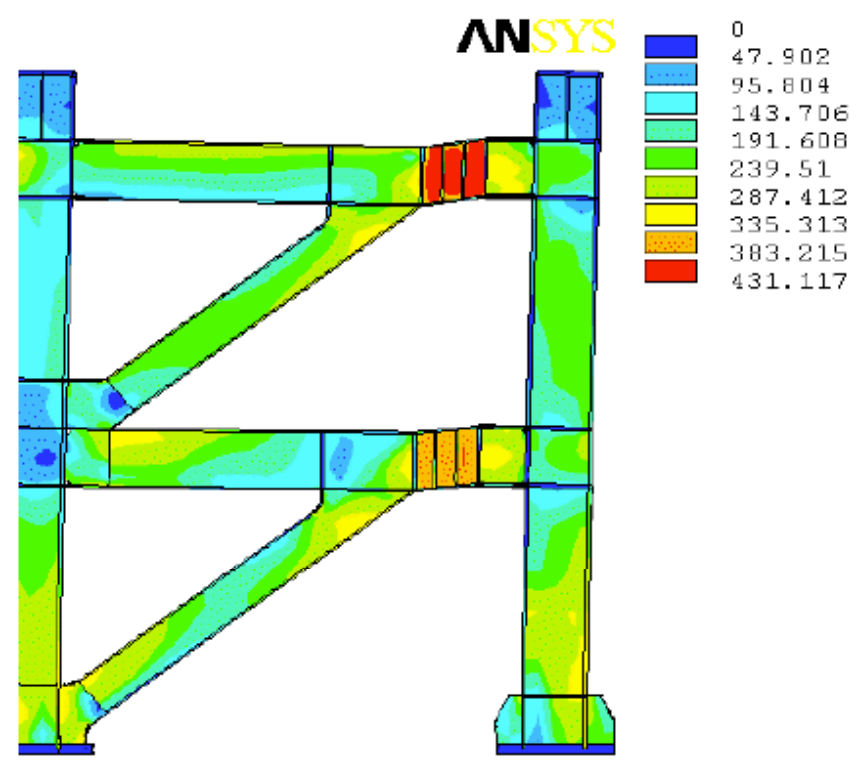

Fig. (17). The stress distributionunder circular loading.

With the thickness of web increasing, the limit capacity and the limit displacement of frame, and the limit rotation capacity of link were obviously improved under unilateral loading. The bearing capacity and energy dissipation capacity of link were increased a little under circular loading. When the structure reached the limit capacity, the link reached the limit strength. The Mises stress in A region was decreased obviously, the stiffness of frame was increased too. When eccentrically brace frame was designed, the web in A region should be supported appropriately to improve resisting seismic behavior of structure.

\section{The Influence of Adding Stiffening Rib in A Region}

Stiffening rib of thickness with $10 \mathrm{~mm}$ in A region was added, and the other parameters were unchanged. Two finite element models were built. One model was built by adding stiffening rib on two sides of web in A region. Another model was built by adding stiffening rib on one side of web in A region. The performance under unilateral loading and cycle loading were calculated by the ANSYS. The results were listed in Table 5. 
Table 4. The Results of Finite Element Analysis

\begin{tabular}{|c|c|c|c|c|c|c|c|c|}
\hline $\begin{array}{c}\text { web } \\
\text { thickness }\end{array}$ & Loading Protocol & $\begin{array}{l}\mathrm{P}_{\mathrm{y}} \\
/ \mathrm{kN}\end{array}$ & $\begin{array}{c}\Delta_{\mathrm{y}} \\
/ \mathrm{mm}\end{array}$ & $\begin{array}{l}\mathrm{R}_{\mathrm{y}} \\
/ \mathrm{rad}\end{array}$ & $\begin{array}{c}\mathrm{P}_{\mathrm{u}} \\
/ \mathrm{kN}\end{array}$ & $\begin{array}{c}\Delta_{\mathrm{u}} \\
/ \mathrm{mm}\end{array}$ & $\begin{array}{c}\mathrm{R}_{\mathrm{u}} \\
/ \mathrm{rad}\end{array}$ & $\mu$ \\
\hline $16 \mathrm{~mm}$ & unilateral loading & 415.8 & 6.56 & $3.72 \mathrm{e}-3$ & 791.8 & 51.56 & 0.1461 & 7.86 \\
\hline \multirow[b]{2}{*}{$14 \mathrm{~mm}$} & unilateral loading & 373.5 & 5.83 & $2.98 \mathrm{e}-3$ & 784.8 & 49.17 & 0.1408 & 8.43 \\
\hline & circular loading & 370.9 & 6 & $2.9 \mathrm{e}-3$ & 740.5 & 36 & 0.1062 & 6 \\
\hline
\end{tabular}

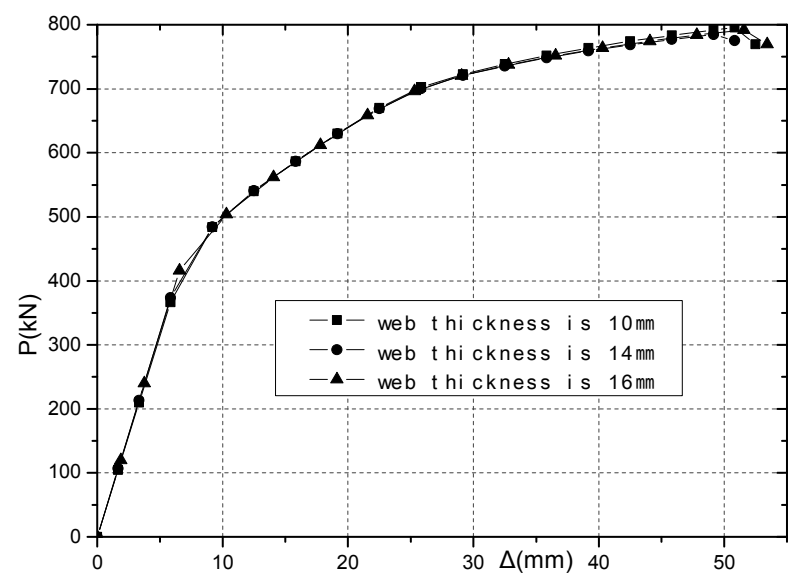

Fig. (18). $P-\Delta$ curve comparing under unilateral loading.

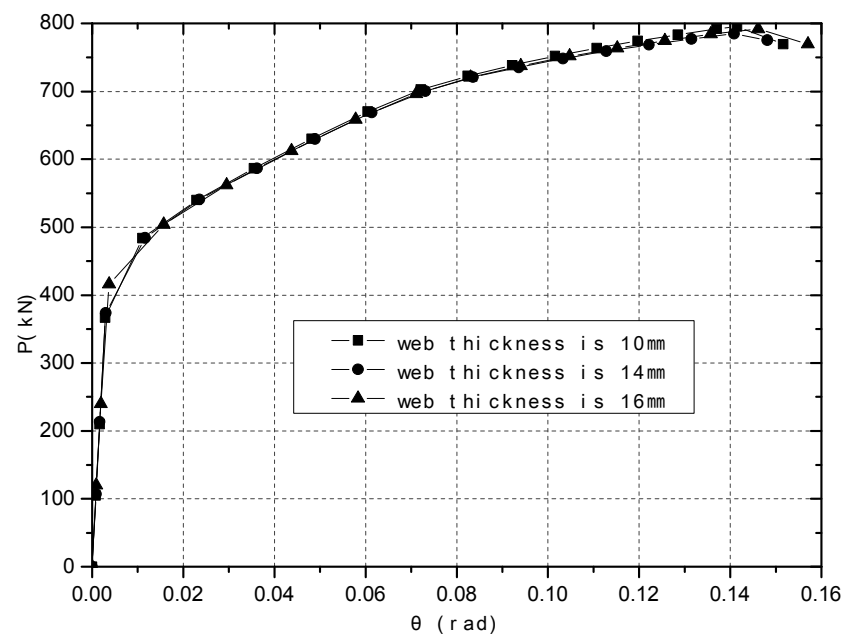

Fig. (19). $\mathrm{P}-\theta$ curve comparing under unilateral loading.

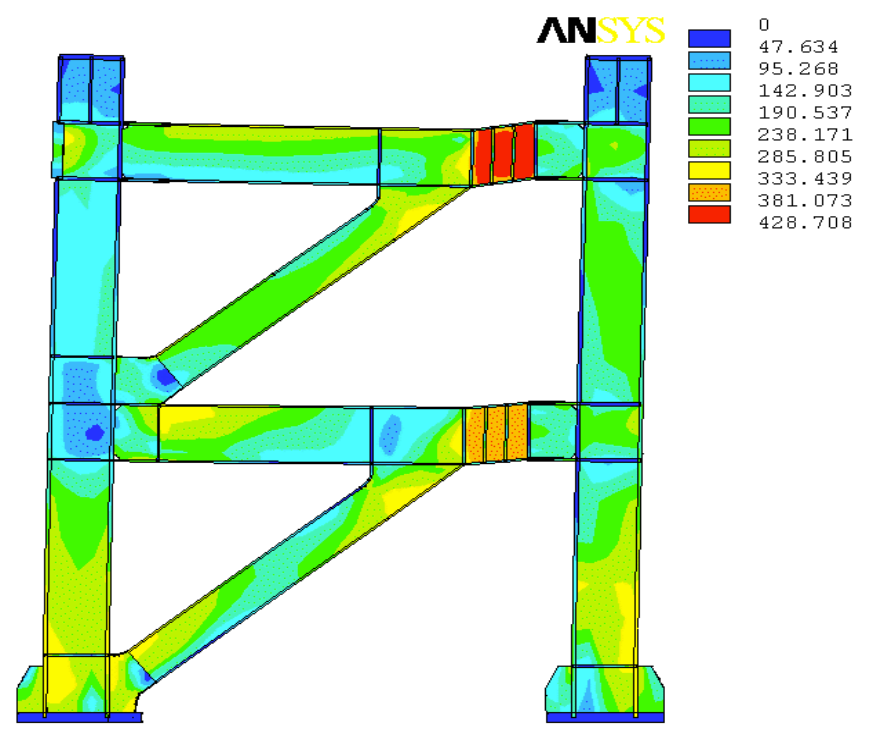

Fig. (20). The stress distribution under circular loading.

The stress distribution of adding stiffening rib on two sides in A region was shown in Fig. (21) when specimen reached the limit capacity under circular loading. The $P-\Delta$ and the $P-\theta$ curve under unilateral loading were presented apart in Figs. (22 and 23). Some conclusion could be drawn as follows.

No matter which was the strengthening measure of adding stiffening rib in A region, the limit capacity and the limit displacement of frame, and the limit rotation capacity of link were obviously improved under unilateral loading, the limit rotation deformation of link was decreased under circular loading. The bearing capacity and energy dissipation capacity of link were increased a little, the stiffness of frame was increased too. The effect of the two strengthening measure was almost same. When eccentrically brace frame was de-

Table 5. The Results of Finite Element Analysis

\begin{tabular}{|c|c|c|c|c|c|c|c|c|}
\hline $\begin{array}{c}\text { Supporting } \\
\text { Protocol }\end{array}$ & Loading Protocol & $\begin{array}{c}\mathbf{P}_{\mathbf{y}} \\
/ \mathbf{k N}\end{array}$ & $\begin{array}{c}\Delta_{\mathbf{y}} \\
/ \mathbf{m m}\end{array}$ & $\begin{array}{c}\mathbf{R}_{\mathbf{y}} \\
/ \mathbf{r a d}\end{array}$ & $\begin{array}{c}\mathbf{P}_{\mathbf{u}} \\
/ \mathbf{k N}\end{array}$ & $\begin{array}{c}\Delta_{\mathrm{u}} \\
/ \mathbf{m m}\end{array}$ & $\begin{array}{c}\mathbf{R}_{\mathrm{u}} \\
/ \mathbf{r a d}\end{array}$ & $\mu$ \\
\hline one side & unilateral loading & 369.8 & 5.83 & $1.895 \mathrm{e}-3$ & 795.6 & 50.83 & 0.09253 & 8.72 \\
\hline \multirow[t]{2}{*}{ two sides } & \multirow{2}{*}{ circular loading } & 367.2 & 6 & $1.843 \mathrm{e}-3$ & 741.5 & 36 & 0.067134 & 6 \\
\hline & & -391.6 & -6 & $-2.1 \mathrm{e}-3$ & -785.9 & -36 & -0.0628 & 6 \\
\hline
\end{tabular}


signed, the measure of adding stiffening rib on one side in A region was adopted to meet enough design requirements.

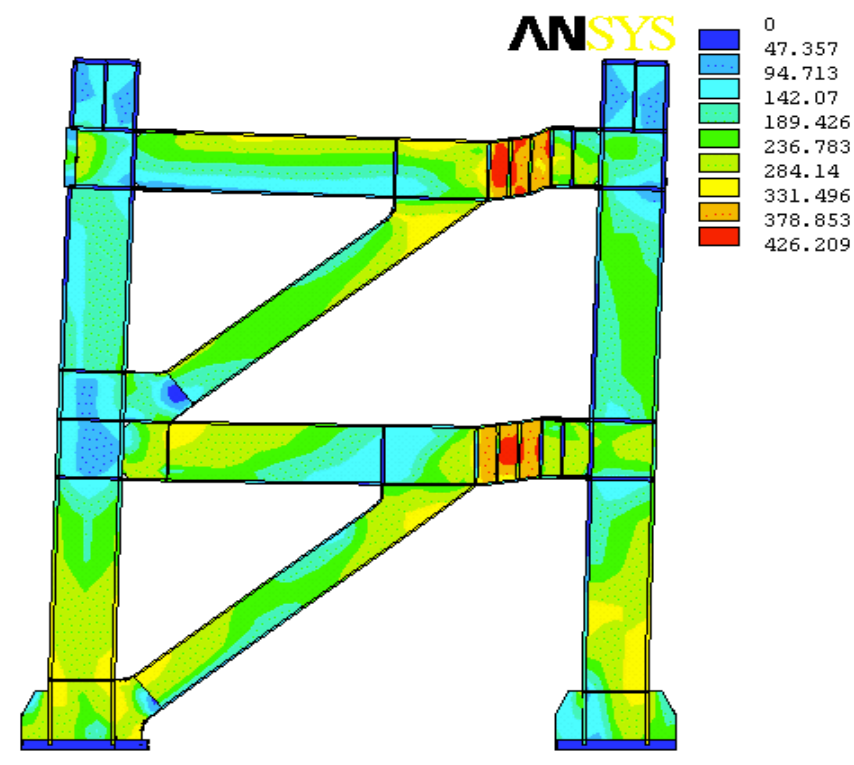

Fig. (21). The stress distribution under circular loading.

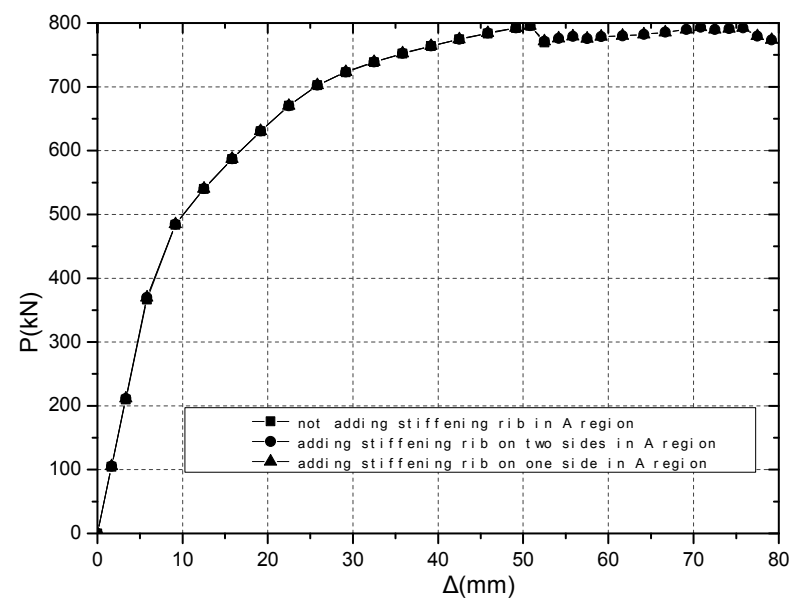

Fig. (22). $\mathrm{P}-\Delta$ curve comparing under unilateral loading.

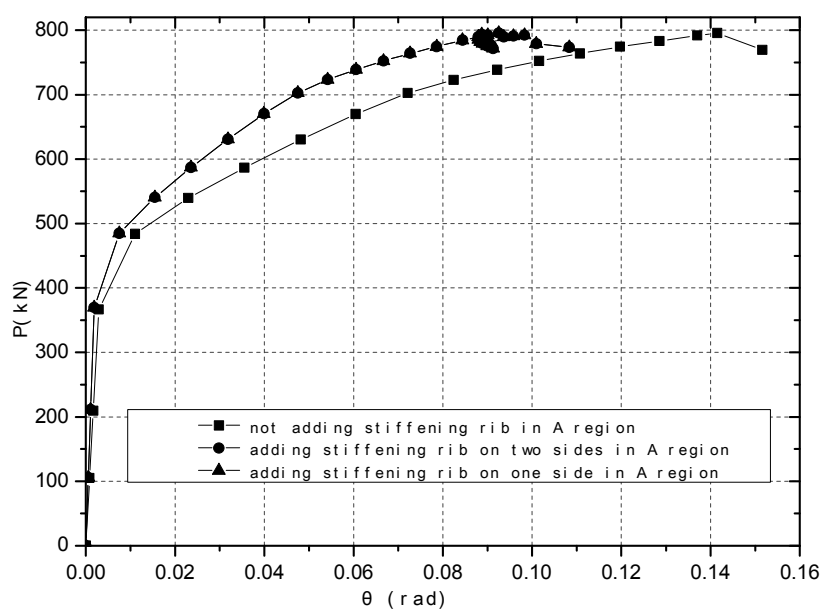

Fig. (23). $\mathrm{P}-\theta$ curve comparing under unilateral loading.

\section{CONCLUSIONS}

The improved cover-plate protocol was applied in D-type eccentrically braced frame. Results from the experimental research and finite element analysis were listed below. But the results need more validation.

1. The new type protocol should satisfy the constructional demand listed in literature9. It could relax the extreme local deformation in the flanges of the links near the column face, allow more rotation of the link, and assure the sufficiency development of plastic deformation. It kept the shear force away from the flange welding of the beam end, and precluded yielding in the link in the region adjacent to the column. It should reduce the mending after the earthquake.

2. The new type scheme not only satisfied the design requirement of strong column, weak beam, stronger joint and flexural capacity, but also assured the EBF good deformation capacity and lateral displacement stiffness.

3. The new type scheme increased the ductility of the specimen, reduced the input of the earthquake energy, and had enough lateral displacement stiffness.

4. The construction details of the new type connection were simple, cheap, and easy to spread.

\section{ACKNOWLEDGEMENT}

The work reported in this paper was financially supported by China's national natural science funds (NO: 51078310) and China's Xian city construction committee.

\section{REFERENCES}

[1] T. Okazaki, "Seismic Performance of Link-to-Column Connections in Steel Eccentrically Braced Frames", PhD thesis, The University of Texas of Austin, USA, 2004.

[2] T. Okazaki, M. D. Engelhardt, "Cyclic loading behavior of EBF links constructed of ASTM A992 steel”, Journal of Constructional Steel Research, vol. 63, pp.751-765, 2007.

[3] Q. Jiaru, C. Maosheng and Z. Tianshen, "Experimental Study and Limit State Analysis of Eccentric-Braced Frames under Horizontal Action", Building Structure, vol. 4, pp.3-9, 1993. (in Chinese)

[4] Z. Baocheng, G. Qiang, "Nonlinear Finite Element Analysis For Eccentrically Braced Steel Frames Under Cyclic Load", China Civil Engineering Journal, vol. 38, pp.27-31, 2005.

[5] People's Republic of China Ministry of Construction, Code for seismic design of building, Beijing: China Architecture Industry Press, 2001.

[6] S. Lin, C. Yiyan, Y. Yinquan, "Design Method of Eccentrically Braced Frames", Building Structure, vol. 2, pp.13, 2002 (in Chinese).

[7] G.S.Prinz, P.W. Richards, "Eccentrically Braced Steel Frame Links With Reduced Web Sections". Journal of Constructional Steel Research, vol. 65, pp.1971-1978, 2009.

[8] T. Okazaki, M. D. Engelhardt, A. Drolias, E. Schell, J-K. Hong, CM Uang, "Experimental investigation of Link-to-Column Connections in Eccentrically Braced Frames". Journal of Constructional Steel Research, vol. 65, pp. 1401-1412, 2009.

[9] J. Hao, X. Pan, "The adding cover-plate protocol used for the shear links-column joints of eccentrically braced frames", China Patent ZL200720032148. 9, 2008. 
[10] L. Qixiang, C. Yiyan, Z. Zhixin and G. Taichang, "A Seismic Design on Beam-Column Joints in Multistory and High Steel Structure", Building Structure, vol. 31, pp. 9-13, 2001. (in Chinese).

[11] People's Republic of China Ministry of Construction, Technical Specification for Steel Structure of Tall Building, Beijing: China Architecture Industry Press, 1998.
[12] People's Republic of China Ministry of Construction, Specification of Testing Methods for Earthquake Resistant Building. Beijing: China Architecture Industry Press, 1997.

[13] J. O. Malley and E. P. Popov, F. ASCE, "Shear Links in Eccentrically Braced Frames", Journal of Structural Engineering, vol. 110, pp.2275-2295, 1984

Received: July 20, 2010

Revised: January 09, 2011

Accepted: January 23, 2011

(C) Pan et al.; Licensee Bentham Open.

This is an open access article licensed under the terms of the Creative Commons Attribution Non-Commercial License

(http://creativecommons.org/licenses/_by-nc/3.0/) which permits unrestricted, non-commercial use, distribution and reproduction in any medium, provided the work is properly cited. 